\title{
EFFECT OF LIGHT POLARIZATION ON HOLOGRAPHIC RECORDING IN GLASY AZOCOMPOUNDS AND CHALCOGENIDES
}

\author{
A.OZOLS, V.KOKARS, P.AUGUSTOVS, I.UISKA, K.TRASKOVSKIS, D.SAHAROV \\ Faculty of Material Science and Applied Chemistry, Riga Technical University \\ Azenes iela 14/24, LV-1007, Riga, Latvia
}

Effect of recording and readout light polarization on holographic grating recording in glassy molecular azobenzene films 8a, 11,16 and glassy chalcogenide a- $\mathrm{As}_{40} \mathrm{~S}_{15} \mathrm{Se}_{45}$ films has been experimentally studied at 633 and $532 \mathrm{~nm}$ with $s-s, p-p$, CE-1 and CE-2 circular-elliptic (differing by light electric field rotation directions) recording beam polarizations. The polarization changes in the diffraction process were studied as well. Azocompounds exhibited much higher self-diffraction efficiency (SDE) and diffraction efficiency whereas chalcogenides were more sensitive . Their recording efficiency polarization dependences also were different and spectrally-dependent. SDE up to $45 \%$ was achieved in 8a with $p-p$ and up to $2.8 \%$ in a- $\mathrm{As}_{40} \mathrm{~S}_{15} \mathrm{Se}_{45}$ with CE-2 polarized recording beams at $633 \mathrm{~nm}$. Linear $p-p$ polarizations were the most efficient at $633 \mathrm{~nm}$ whereas CE-1 polarizations were the best at $532 \mathrm{~nm}$ in azocompounds. It was found that light polarization changes in the process of diffraction depended on chemical composition, wavelength and exposure time. Vector gratings with SDE up to $25 \%$ were recorded in $\mathbf{8 a}$ rotating a linear polarization by $90^{\circ}$. No light polarization changes were found in chalcogenide films. Coherent self-enhancement of gratings was observed only in azocompounds for $s-p$ and both CE polarizations in 8a at 532 $\mathrm{nm}$, and for $s-p$ polarizations at $633 \mathrm{~nm}$. The evidence is found for trans-cis photoisomerization holographic recording mechanism at both 532 and $633 \mathrm{~nm}$.

Keywords: light polarization, holographic gratings, azocompounds, chalcogenides

Corresponding author e-mail: aozols@latnet.lv 